\title{
Efecto de la Iniciativa de Transparencia para el sector extractivo en Perú
}

\author{
The Effect of the Transparency Initiative \\ for the Extractive Sector in Peru
}

Efeito da Iniciativa de Transparência para o setor extrativista no Peru

\section{Carlos Olmedo Cruz}

Universidad Kyung Hee. Suwon, Corea del Sur colmedocv@yahoo.es

https://orcid.org/0000-0002-8150-8556

\section{Ibeth López Cazar}

Instituto Internacional de Estudios Sociales. La Haya, Países Bajos ibeth_mlc@hotmail.com

https://orcid.org/0000-0001-6859-7884

DOI: https://doi.org/10.32719/25506641.2022.11.5

Recibido: 5 de abril de 2021 - Revisado: 12 de mayo de 2021

Aceptado: 26 de junio de 2020 - Publicado: 1 de enero de 2022

Artículo de investigación

Licencia Creative Commons

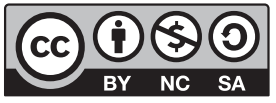




\section{Resumen}

El problema de la corrupción en Latinoamérica tiene una larga historia con raíces profundas. Los enfoques para tratar la corrupción son diversos, sin embargo, producen mayor interés los casos que, teniendo abundante riqueza natural, no lograron su desarrollo pleno como nación. La Iniciativa para la Transparencia de las Industrias Extractivas (EITI) se ha implementado en el Perú como una propuesta para abordar la corrupción y determinar su aporte en la gobernabilidad del sector extractivo nacional y local en torno a mejores condiciones de transparencia. Este estudio ha utilizado la teoría de la maldición de los recursos y la metodología de control sintético (MCS) con el fin de analizar el efecto de la EITI en los niveles de corrupción en un país líder exportador minero como Perú. La MCS es ideal para muestras cualitativas en estudios de casos en ciencia política, como es la intervención de EITI en Perú. El caso constituye un aporte a la literatura, toda vez que la mayoría de los estudios relativos se los ha realizado en la totalidad de los países, siendo pocos los estudios de casos individuales. Los resultados no se muestran estadísticamente significativos luego de su aplicación en el tratamiento de casos de corrupción del sector extractivo que, dadas sus características profundas, requiere mayor intervención gubernamental y participación de la sociedad civil; es decir, la investigación muestra que la EITI no ha tenido efecto en la reducción de la percepción de corrupción en Perú.

Palabras clave: Iniciativa para la Transparencia de las Industrias Extractivas, corrupción, Perú, metodología de control sintético, transparencia.

JEL: C1 Métodos econométricos y estadísticos: generalidades.

\section{Abstract}

The problem of corruption has a long deep-rooted history in Latin America. The approaches to deal with corruption are diverse; however, the cases of most interest are those that, despite having abundant natural wealth, did not achieve their full development as a nation. The Extractive Industries Transparency Initiative (EITI) has been implemented in Peru as a proposal to address corruption and determine its contribution to the governance of the national and local extractive sector based on better transparency conditions. This study used the resource curse theory and the Synthetic Control Methodology (MCS, as per its Spanish acronym) in order to analyze the effect of EITI on the levels of corruption in a leading mining exporting country like Peru. The MCS is ideal for qualitative samples in political science case studies, such as the EITI intervention in Peru. The case constitutes a contribution to literature, since most of the related studies have been carried out in all countries as a whole, with few studies of individual cases. The results are not statistically significant after applying it to the management of corruption cases in the extractive sector, which requires greater government intervention and civil society participation, given its profound characteristics. In other words, the study shows that the EITI has had no effect on reducing the perception of corruption in Peru.

Keywords: The Effect of the Transparency Initiative, corruption, Peru, MCS, transparency.

JEL: C1 Econometric and statistical methods: generalities. 


\section{Resumo}

O problema da corrupção na América Latina tem uma longa história com raízes profundas. Os focos para tratar o tema da corrupção são diversos, contudo, produzem maior interesse os casos em que, tendo abundante riqueza natural, não conseguiram seu desenvolvimento pleno como nação. A Iniciativa para a Transparência das Indústrias Extrativas (EITI) foi implementada no Peru como uma proposta para abordar a corrupção e determinar sua contribuição na governabilidade do setor extrativo nacional e local em torno a melhores condições de transparência. Este estudo tem utilizado a teoria da maldição dos recursos e a Metodologia de Controle Sintético (MCS) com a finalidade de analisar o efeito da EITI nos níveis de corrupção no país líder exportador minero como Peru. A MCS é ideal para amostras qualitativas em estudos de casos em ciência política, como é a intervenção da EITI no Peru. O caso constitui um aporte à literatura, toda vez que a maioria dos estudos relativos foram realizados na totalidade dos países, sendo poucos os estudos de casos individuais. Os resultados não se apresentam estatisticamente significativos depois de sua aplicação no tratamento de casos de corrupção do setor extrativo que, dadas suas características profundas, requer maior intervenção governamental e participação da sociedade civil; ou seja, a investigação mostra que a EITI não há tido efeito na redução da percepção da corrupção no Peru.

Palavras-chave: Efeito da Iniciativa de Transparência, corrupção, Peru, MCS, transparência. JEL: C1 Métodos econométricos e estatísticos: generalidades.

\section{Introducción}

$\mathrm{D}$ os de los grandes males que impiden el desarrollo de los países son la destrucción del medioambiente y la corrupción. La corrupción se transformó, del abuso corporativo del poder, en la década del 70, al abuso gubernamental del poder en los 90 (Katzarova 2018). Sin embargo, estos modelos no son exclusivos de las últimas décadas. La historia de la corrupción en América Latina puede entenderse desde la dimensión de su amplia riqueza, la pobreza del hombre como resultado de la riqueza de la tierra (Galeano 2014). Warf y Stewart (2016) describen que el modelo de las instituciones que trabajarían en América Latina se definió durante el período colonial. Los conquistadores pusieron en práctica toda clase de comportamientos denigrantes en la obtención de los recursos: engaño, destrozos, codicia, traición, indolencia. Tenochtitlán y Cuzco fueron arrasadas para la obtención del oro (Quiroz 2014). 
La aristocracia española tenía como modo de vida el despilfarro, la acumulación de tierra, compra de títulos de deuda de la corona para una vida rentista y la compra de títulos de nobleza. Los recursos mineros no se invertían en el desarrollo industrial. La situación económica de España se caracterizó por lo que se conoce como la maldición de los recursos, riqueza de recursos sin desarrollo (Manzano y Rigobon 2001). Este modelo sería replicado en los territorios de ultramar en los virreinatos donde, distantes del control, se cometerían los mayores abusos para la población nativa original. Una misión enviada desde España viajó a América Latina ${ }^{1}$ para encargarse de describir las disfunciones y abusos administrativos observados de manera directa en Lima, Quito, Cartagena, Panamá y los puertos de Chile entre 1736 y 1744. Así, la historia de América Latina está relacionada con el extractivismo. Se destaca la administración corrupta en el asiento minero de Huancavelica, manejada en forma negligente desde su explotación, causando frecuentes derrumbes que mataban a muchos nativos que trabajaban en las minas. Las autoridades no castigaban esta práctica abusiva y costosa, había impunidad, así como fraude en la recepción y contabilidad de rentas reales, en los actos administrativos y la justicia se administraba en función del cohecho (Eguren, De Belaunde y Burga 2005).

En Huancavelica, el sector minero en Perú inicia su actividad durante la época colonial, creándose una legislación relativa apenas iniciado el siglo XX con el Código de Minería de 1901, luego los de 1950, 1971, 1981 para finalmente establecer la Ley General de Minería de 1992 que promueve las inversiones en el sector minero y libera la comercialización interna y externa; esta última ley es la que se mantiene vigente (Dammert Lira y Molinelli Aristondo 2007).

Perú es un país primario exportador y de servicios. La agricultura, gas, minería y recursos marinos son los componentes principales. Su economía tiene alta dependencia de la exportación de minerales, el sector minero representa el $60 \%$ y el sector de hidrocarburos el 3,2\% del total de las exporta-

1. En 1735 Antonio de Ulloa y Jorge Juan viajaron por orden de Felipe V para unirse a la expedición de seis personas de la Academia de Ciencias de París con Jean Charles de la Condamine que asistieron para medir el arco de la Tierra en Quito. El objetivo de la misión era mandar información estratégica acerca del manejo administrativo y económico que se daba en los virreinatos. 
ciones (MINEM 2021a). La producción minera de Perú está concentrada en siete minerales: cobre $30 \%$, oro $18,5 \%$, zinc $4 \%$, plomo $3,4 \%$, hierro $2,7 \%$, estaño $0,8 \%$ y plata $0,2 \%$, posicionándose como uno de los principales productores de metales básicos y preciosos del mundo (OSINEGMIN 2019). Las regiones de mayor producción minera son Áncash, Arequipa, Cajamarca, Moquegua y Apurímac. La producción minera en el 2019 representó el 9\% del PIB y la de hidrocarburos el 3\% (OSINERGMIN 2019). Todas las regiones mineras de Perú producen la mayoría de los minerales donde se identifican algunas empresas explotadoras de dichos materiales (Dammert Lira y Molinelli Aristondo 2007). ${ }^{2}$

El sector de hidrocarburos de Perú data de 1948 con la creación de la Empresa Petrolera Fiscal (EPF) del Estado. La empresa estatal Petroperú creada en julio de 1969 complementa las actividades de refinación y comercialización (Bolaños 2017). Según el Ministerio de Energía y Minas del Perú (MINEM 2021b), la producción de hidrocarburos es de 120000 barriles diarios.

En la región de Piura se concentra la producción de crudo, en la localidad de Talara, así como en Tumbes y Loreto. A finales de los 70 la migración a Talara se incrementó de manera intensa, con lo que el Estado no logró cubrir las necesidades básicas de los nuevos pobladores. Durante la década del 90 el centralismo y clientelismo intensificaron la problemática (Del Castillo 2015). Frente a este escenario, en 2006 se creó el mecanismo de Mesa de Diálogo de Responsabilidad Social (MDRS) para conducir el desarrollo de la provincia de Talara. Este mecanismo realiza reuniones periódicas con autoridades locales, funcionarios públicos, gerentes de las empresas petroleras, presidentes de colegios profesionales y periodistas, entre otros. Pero la participación de las empresas es limitada y con representación incompleta de actores ante la MDRS que es utilizada para otros fines como ejercer presión política a autoridades locales (Del Castillo 2015).

2. En la producción de los siete minerales principales se identifican algunas empresas donde se concentra la producción de un determinado mineral. La Compañía Minera Antamina S. A. y Southern Perú Copper Corporation Sucursal del Perú concentran el 37 y $35 \%$ respectivamente. Estaño, el $100 \%$ de la producción la concentra Minsur S. A. Hierro, produce en su totalidad Shougang Hierro Perú S. A. A. En la producción de oro, destacan la Minera Yanacocha S. R. L. (40\%) y Minera Barrick Misquichilca S. A. (26\%) (Dammert Lira y Molinelli Aristondo 2007). 
En consecuencia, las prácticas que conforman el entorno de la corrupción en Perú se encuentran vigentes hoy en día; describen los principales problemas al que se enfrentaría la implementación de una política pública anticorrupción, procesos de transparencia o nuevas legislaciones en torno al tema (Correa 2012). Uno de los mecanismos de anticorrupción es la Iniciativa de Transparencia en las Industrias Extractivas (EITI, por sus siglas en inglés) definido como el estándar para promover la gestión responsable de los recursos minerales de los sectores estratégicos, que ha manifestado la necesidad de tener una gobernanza adecuada, transparente, que no sea presa de la ineficiencia y la corrupción. Los esquemas de corrupción son entramados complejos vinculados al poder. Este elemento es un determinante para la efectividad del mecanismo EITI por cuanto el compromiso por parte del gobierno determinará el nivel de impacto que se alcance. El objetivo del estudio es medir el efecto que la EITI ha tenido en los niveles de corrupción del Perú. La implementación de EITI busca transparentar la gestión de los recursos minerales y eficiencia en el manejo de los ingresos, evitando el fenómeno de la maldición de los recursos que durante repetidos períodos de la historia económica de Perú ha incidido.

En consecuencia, esta investigación contribuye a la literatura en cuanto a los estudios individuales sobre el efecto de la EITI en la reducción de la corrupción. Así, este tema es relevante en el campo de estudios de gestión ya que permite validar un esquema o iniciativa anticorrupción con creciente aceptación a nivel de países; sin embargo, la efectividad de la EITI no está afianzada definitivamente. La mayoría de estudios se los ha realizado con paneles de datos y puntajes de propensión, siendo pocos los estudios de casos individuales. La metodología de control sintético (MCS) permite conocer a profundidad lo que pasa en un país luego de la introducción de la EITI y en cada etapa de su desarrollo. Esta metodología corrige las limitaciones de las series de tiempo y métodos de diferencia en diferencia (Abadie, Diamond y Hainmueller 2015). La unidad sintética modelada con la contribución de variables predictoras de países específicos nos da una idea del impacto de la EITI en Perú. Si bien ya se realizó un estudio en la región, en la que también consta Perú (Etter 2012), este carecía de pruebas de inferencia. Adicionalmente, es importante profundizar en este país, pues fue el primero en unirse a la EITI en Latinoamérica y ha llegado a ciertos niveles locales. Se espera que este estudio sea un caso de análisis para los demás países de la región. 


\section{Revisión de la literatura}

La buena gobernanza de los recursos naturales puede prevenir la maldición de los recursos, lo cual se traduce en desarrollo y crecimiento. La teoría de la maldición de los recursos trae consigo la paradoja de tener recursos minerales y no generar el crecimiento esperado. Esto demuestra las fallas de los sistemas de gobernanza para administrar la riqueza de los países (Vieyra y Masson 2014). El sector extractivo debe gestionarse con transparencia y eficiencia para fomentar el crecimiento económico y reducir la pobreza (Pegg 2006).

\section{Dimensión de la teoría de la maldición de los recursos y sus variables}

La maldición de los recursos indica que tener recursos minerales tales como petróleo, gas y otros minerales, tiene una relación negativa con el crecimiento económico (Auty 1994). Esta teoría aborda el fracaso de los sistemas económicos, incluidos los políticos y sociales (Weszkalnys 2011).

En la década de los 50 y 60, varios estudios macroeconómicos argumentaron que la dotación de recursos podría traer impactos económicos positivos a largo plazo. Esto se debe a que los países invertirían en áreas sociales y tecnológicas, innovación, desarrollo y alivio de la deuda externa, siendo más una bendición que una maldición (Lewis 2013; Watkins 1963). Sin embargo, esta hipótesis se convirtió en la excepción en lugar de la regla (Collier 2008). En 1977 se introdujo una variante de la teoría de la maldición de los recursos, la enfermedad holandesa, debido a los hallazgos del campo de gas natural de Groningen (costa noreste del Mar del Norte de los Países Bajos) y al impacto que tuvo en la economía holandesa como la apreciación de la moneda, pérdida de competitividad de otros productos exportables, declive del sector manufacturero y desempleo (Gunesch 2018).

La maldición de los recursos, según Manzano y Rigobon (2001), se explica por el aumento de la deuda, ya que los recursos minerales sirven como garantía, provocando posteriores crisis de deuda (sobreendeudamiento). Otros aspectos asociados a la maldición de los recursos son la democracia y 
el conflicto. En ausencia de democracia (regímenes autocráticos) durante los auges de precios de los minerales, existe una tendencia a gastar más, lo que genera incertidumbre macroeconómica (Gilberthorpe y Papyrakis 2014). Ross (2001), con su investigación empírica, concluye que los gobiernos con riqueza mineral pueden controlar y manipular los diferentes sectores como las corporaciones mediáticas para prevenir las aspiraciones democráticas. Con respecto a la variable de conflicto, se sugiere que la presencia de recursos minerales podría conducir a un conflicto violento debido a una distribución desigual de esos recursos (Collier y Hoeffler 1998; Collier, Hoeffler y Rohner 2009). Gilberthorpe y Papyrakis (2015) expresan, en consecuencia, que los problemas pueden surgir, por ejemplo, en comunidades indígenas donde las personas tienen que adaptar su cultura a actividades extractivas con costumbres y procedimientos occidentales (Papyrakis 2017).

Un enfoque importante de la teoría de la maldición de los recursos es la relación con la dimensión institucional, que involucra eficiencia gubernamental, estado de derecho, rendición de cuentas y corrupción, entre otros. Algunos estudios afirman que las industrias extractivas impiden el desarrollo de un buen marco institucional porque las rentas obtenidas de los recursos minerales son un incentivo para la búsqueda de rentas, mismas que provocan desviaciones de fondos a expensas de la riqueza de toda la población, afectando a las instituciones (Krueger 1974; Orogun 2010; Ross 2001; Villar y Papyrakis 2017).

Las rentas mineras pueden causar ineficiencia en la asignación de fondos públicos, con burocracia y políticos de baja calidad, políticas de corto plazo debido a la volatilidad de los precios de los minerales, controles insuficientes de transparencia y de estado de derecho, dañando a las instituciones e impidiendo el buen gobierno (Karl 1997; Kolstad y Wiig 2009; Stevens y Dietsche 2008).

Las instituciones también pueden verse afectadas por regímenes autoritarios que intentan frenar la rendición de cuentas, canalizando los ingresos minerales para fortalecer su supremacía y permanecer en el poder (Andersen y Ross 2014; Aslaksen 2010; Tsui 2011). Por otro lado, las buenas instituciones - baja corrupción, burocracia eficiente, seguridad en el acceso a la propiedad, entre otras - pueden tener un papel mediador para obstaculizar la maldición de los recursos (Boschini, Pettersson y Roine 2007; Kolstad 2009; Sarmidi, Hook Law y Jafari 2014). En otras palabras, instituciones sólidas 
en países ricos en recursos evitan que las industrias extractivas compitan ilegalmente por las rentas. La baja corrupción y la buena gobernanza mejoran los controles y, por lo tanto, conducen a un crecimiento económico deseable (Calder y Culverwell 2005).

\section{La EITI, validación y algunas evaluaciones determinantes}

La EITI sirve a los países para aumentar la transparencia, hacer frente a sus problemas de corrupción y mejorar la gobernabilidad en el sector extractivo. El mecanismo de esta iniciativa consiste básicamente en la divulgación de información sobre los pagos realizados tanto por el gobierno como por las empresas extractivas (Papyrakis, Rieger y Gilberthorpe 2017). Los países se adhieren voluntariamente e implica el compromiso de los gobiernos. Se involucra a los actores sociales que tradicionalmente han sido excluidos, como medios de comunicación, organizaciones no gubernamentales, fondos de inversión privados y comunidades indígenas, en el manejo de los recursos minerales, que ahora interactúan para dar forma a reglas, normas y políticas en el sector, a través de la formación de un grupo de multipartícipes: gobierno, empresas y sociedad civil (Vieyra y Masson 2014).

Los países que se suman a esta iniciativa deben pasar por estas etapas: compromiso, candidatura y cumplimiento (EITI Perú 2016b). ${ }^{3}$ Además, deben cubrir los fondos para realizar las actividades y los costos generados en el proceso de implementación (desde USD 100000 hasta varios millones por

3. Compromiso: el gobierno se compromete con la EITI a través de un documento público que garantice su implementación. El grupo de múltiples partes interesadas establece un plan para la divulgación de la información y la mejora de la transparencia (EITI Perú 2016b).

Candidatura: cumplidos los requisitos iniciales, el grupo de multipartes solicita al Consejo de la EITI obtener su estatus de candidato.

Cumplimiento: el país debe cumplir los requisitos de la EITI con: grupo de multipartes activo, divulgación de información del sector minero, información de exploración y producción, flujos financieros, asignación de ingresos, gasto social y económico, y presentación de la información junto con los diálogos de la sociedad civil. El progreso realizado por el país lo revisa el Consejo de la EITI (EITI Perú 2016b). 
año, según el plan elaborado por cada país). Algunos países pueden obtener apoyo financiero de organizaciones internacionales de desarrollo como el Banco Mundial (EITI Perú 2016b).

La limitación de esta iniciativa es que la corrupción puede estar presente en las distintas etapas del proceso. Por ejemplo, Kolstad y Wiig (2009) mencionan que el grupo de multipartícipes puede caer en la tentación de la búsqueda del rentismo y el patrocinio. Otros investigadores dicen que los Estados miembros de la EITI y el sector privado no revelarían información completa y consistente (Dykstra 2011; Gillies y Heuty 2011; Ravat y Ufer 2010). Según Lujala, Aas Rustad y Le Billon (2017), la EITI limita su percepción de la corrupción porque abarca solo un sector de la corrupción de todo el país; por tanto, sus efectos pueden ser discutibles. Más aún, Dykstra (2011) y Van Alstine (2017) afirman que la contribución de la sociedad civil puede verse restringida durante el proceso.

Se han realizado varios tipos de investigaciones con el propósito de evaluar la validez de la EITI. Por lo general, las evaluaciones se han concentrado en estimar el efecto promedio de la EITI en todos los países participantes y pocos en estudios de casos individuales.

Utilizando el análisis de paneles, Corrigan (2017) encontró que la corrupción puede reducirse en la etapa de compromiso cuando los gobiernos comienzan a realizar acciones para convertirse en candidatos dentro del mecanismo EITI. En la misma línea, Papyrakis, Rieger y Gilberthorpe (2017) sugirieren que los países que participan en este esquema tienden a protegerse contra la propensión hacia la corrupción, especialmente en la segunda etapa candidatos, donde los países realizan el mayor esfuerzo para lograr el estatus de cumplimiento.

Por otro lado, Öge (2016), igualmente con paneles de datos, encontró que la corrupción no cambió ( $\operatorname{cin}$ significación estadística). Kasekende, Abuka y Sarr (2016), con una metodología de máxima probabilidad de información completa (FIML), encontraron que no hay indicios de que la corrupción haya disminuido después de adoptar la EITI. Sovacool et al. (2016) analizaron 16 países que lograron el estado de cumplimiento de la EITI (utilizaron una prueba no paramétrica y un análisis de regresión), infirieron que los países del EITI no obtienen mejores resultados en las métricas de gobernanza. 
Los estudios de casos individuales brindan más información para contrarrestar o respaldar los resultados obtenidos en los análisis implementados en todos los miembros de la EITI. A través de la MCS, Villar y Papyrakis (2017) presentan evidencia de reducción de la corrupción en Zambia, especialmente en etapas previas para obtener el estado de candidatura y cumplimiento. También Etter (2012) determinó el impacto positivo de la EITI en la reducción de la corrupción en Perú, pero sin ningún efecto en Mali.

Otros estudios, basados en investigaciones cualitativas acerca del desempeño de la EITI, son el de Sovacool y Andrews (2015) sobre Azerbaiyán y Liberia en 2009, quienes encontraron una reducción de la corrupción en Azerbaiyán, pero no en Liberia; argumentan que la implementación del EITI difícilmente mejora la gobernanza. Los resultados de Hoinathy y Jánszky (2017) en Chad, encontraron que el efecto de la EITI sobre la corrupción y la pobreza es muy limitado, mientras que los beneficios permanecen en las compañías petroleras y el Estado.

\section{Metodología}

Se escogió la metodología de control sintético (MCS) para realizar este análisis debido a que este método es ideal para pequeñas muestras con características cualitativas como estudios de casos en ciencia política. Sirve para analizar los efectos de intervenciones políticas, como es la EITI en Perú. Este método, en lugar de usar unidades comparativas subjetivas a discreción del investigador, tiene un enfoque basado en datos que permite obtener una o más combinaciones de posibles unidades que más se acercan a la unidad de estudio (Abadie, Diamond y Hainmueller 2010). Al usar la MCS, las unidades producidas son el contrafactual que no ha sido objeto de ninguna intervención con características similares a la unidad de estudio (Abadie, Diamond y Hainmueller 2015). Las unidades comparativas usadas en el estudio reciben diferentes pesos, mismas que producen una unidad sintética que más se apega al comportamiento de la unidad tratada en el período de preintervención; luego de la intervención la unidad sintética refleja el comportamiento de que la unidad tratada hubiera tenido sin dicha intervención. La diferencia entre estas dos unidades es el efecto de la intervención o decisión política. 
La ventaja de este método comparado con los otros, por ejemplo, con la metodología diferencia en diferencia, es que la MCS no asigna a todas las unidades no tratadas el mismo peso. En su lugar, el peso promedio dado a las unidades de control es más alto cuando hay mayor similitud a la unidad tratada en el período de preintervención. Luego, en el período posterior a la intervención, los resultados son proyectados usando los pesos asignados, creando así el contrafactual de la unidad estudiada (Galiani y Quistorff 2017). Adicionalmente, esta metodología permite realizar pruebas de placebo para verificar la significancia estadística de los resultados entre la unidad sintética y la unidad tratada (Abadie y Gardeazabal 2003; Abadie, Diamond y Hainmueller 2010). Dos pruebas de placebo se usan en esta investigación. La primera consiste en volver a aplicar la MCS al grupo de donantes para obtener una distribución de los efectos placebo en el lugar denominado como "no restringido" (Galiani y Quistorff 2017). El segundo método consiste en restringir el grupo de donantes a aquellos que mejor se adapten a la unidad intervenida, denominado "Ajustado estandarizado no restringido" (Galiani y Quistorff 2017). Finalmente, con este método, tanto las variables observadas como no observadas en el período de preintervención tienen una relación lineal, por lo que es posible predecir los resultados de las variables no observadas (Abadie, Diamond y Hainmueller 2010).

\section{Presentación, análisis y discusión de resultados}

El estudio usa el período 2002-2017 para evaluar el efecto de la EITI en la variable de "corrupción política" en Perú. En 2002 fue cuando la EITI empezó operaciones. Antes de este año, no había ninguna intervención de la EITI en el mundo, por lo que usar años previos no tendría ningún valor agregado para obtener la unidad sintética de Perú. Esto es, todos los países fueron unidades de control, considerando que Perú se unió en 2005, se tiene un período de tres años para generar la unidad sintética. Adicionalmente, el año 2017 es el límite puesto que las bases de datos contenían la información hasta dicho año.

La MCS permite ver el efecto de la intervención, no solo en el período que el evento ocurrió, sino también en los subsiguientes. Por esta razón, el 
modelo es aplicado en el primer año de intervención cuando los gobiernos empiezan a tomar acciones para reducir la corrupción, y se puede observar el efecto en los años subsiguientes cuando avanzan con el proceso y trámites correspondientes. En la figura 1 se puede ver la trayectoria de Perú en cuanto al avance de implementación de la EITI.

Se encontró en la página web de la EITI la información del progreso de implementación, así como en los reportes anuales, reportes de validación o publicaciones de la EITI.

Figura 1

\section{Año de cada etapa de implementación en el Perú}

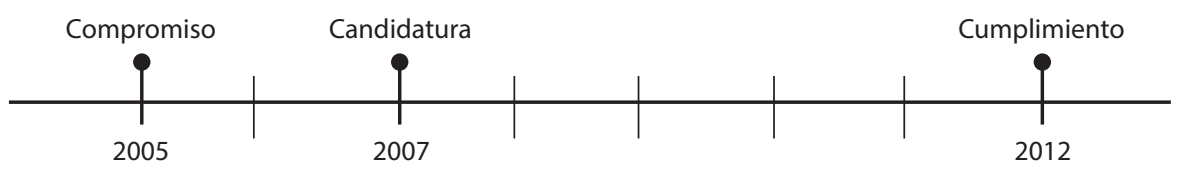

Fuente: adaptado de EITI (2018).

\section{Variables de resultado}

Con el afán de evaluar el efecto de la EITI en la corrupción de Perú, se usó una variable de resultado de la base de datos de variedades de democracia (V-Dem). Esta base construye indicadores agregados de gobernanza por país con la ayuda de subíndices que vienen de bases de datos de diferentes organizaciones. Las mediciones reflejan la percepción de los ciudadanos sobre la corrupción (actores de la esfera pública y privada, a nivel empresarial o familiar), en este caso, de Perú.

El indicador de resultado usado es "corrupción política" de V-Dem 2019 que lleva las medidas de 0 a 1 , en donde 0 es menos corrupto y 1 más corrupto. Este indicador mide seis tipos de corrupción que cubren diferentes áreas y niveles del campo de la política, incluyendo la corrupción del ejecutivo, legislativo y judicial. Por lo tanto, esta medida incluye diferentes tipos de corrupción, tanto a pequeña como a gran escala, soborno y robo, corrupción que influye 
en la elaboración de leyes y que afectan a su implementación (Varieties of Democracy V-Dem 2019). Dado que esta variable incluye los mencionados tipos corrupción en su amplio aspecto, es la más idónea para medir la corrupción tanto a nivel nacional como local en Perú.

\section{Variables predictoras}

Para construir la unidad sintética de Perú, es necesario usar un cierto número de variables predictoras. Estas variables se han seleccionado de acuerdo a la literatura que mencionan las posibles causas de corrupción. Por ejemplo, Serra (2006) y Treisman (2000) encontraron que las variables que determinarían la corrupción son: desarrollo económico, religión, herencia colonial, democracia ininterrumpida, y estabilidad política. Shabbir y Anwar (2007) indican como variables que explicarían la corrupción en países en desarrollo: la libertad económica, distribución de ingresos, nivel de desarrollo y globalización. Ades y Di Tella (1999), Brunetti y Weder (2003) y Persson, Tabellini y Trebbi (2003) resaltan que la corrupción está relacionada con la apertura al comercio internacional, libertad de información y el sistema electoral. Información adicional sobre los determinantes de corrupción se puede encontrar en: Elbahnasawy y Revier (2012), Ata y Arvas (2011), Jain (2001), Park (2003) y Ali e Isse (2003). Con base en estas evidencias, esta investigación usa variables predictoras similares o aproximadas para construir la variable sintética de corrupción de Perú. En el anexo 1 se describen las variables usadas. Adicionalmente, se incluye la variable de corrupción como predictora debido a que reduce la sensibilidad en el proceso de pesos de las variables no observadas y ayuda a un mejor emparejamiento entre la unidad de control y la sintética (Villar y Papyrakis 2017).

\section{Resultados}

Al usar la MCS para crear la unidad contrafactual, el análisis se basa en un grupo de países donantes que no han recibido la intervención de la EITI; 
102 países con información disponible obtuvieron un conjunto de valores que se promediaron para estimar la unidad sintética que más se acerca a la unidad tratada de Perú. La MCS permite apreciar los países que contribuyen en mayor medida a formar la unidad sintética, cuyos valores en combinación suman 1 (Abadie, Diamond y Hainmueller 2010). El anexo 2 incluye los valores por país que más afectan a la generación de la unidad contrafactual.

Adicionalmente, la MCS permite ver en la figura 2 la similitud entre la unidad sintética y la real antes de la preintervención. Los resultados obtenidos por las variables observadas y no observadas muestran la capacidad de la unidad sintética para predecir el comportamiento que la unidad tratada tendría sin la intervención de la EITI en el transcurso del tiempo. También, la metodología permite conocer que los valores por variable predictora tienen paridad entre la unidad sintética y tratada (anexo 3). En la figura 2 es evidente que la unidad sintética y tratada siguen la misma trayectoria en la etapa de preintervención hasta 2005 de compromiso.

Posteriormente, con el método de inferencia se obtienen los efectos de placebo que producen la significancia estadística. El método genera el cambio en el tamaño de la brecha para cada año del período posterior a la intervención con la significación estadística de los métodos usados "no restringido" y "ajustado estandarizado no restringido". Los resultados muestran una mayor significancia estadística para el método "ajustado estandarizado no restringido". Al aplicar el método "no restringido", las distribuciones de brechas de placebo pueden variar muy lejos del resultado del país donante promedio, por lo que la lejanía de estas distribuciones distorsiona las estimaciones de los valores $p$. En este sentido, los valores $p$ informativos presentados en la representación gráfica de Perú son el "ajustado estandarizado no restringido".

Luego de haber corrido la metodología de control sintético para Perú, se puede evidenciar en la tabla 1 que la tendencia de comportamiento de la unidad sintética es diferente a la unidad tratada de Perú desde 2005. En las figuras 2 y 3 se presenta el comportamiento de la unidad sintética y tratada. 
Tabla 1

Trayectoria de la variable de resultado luego de usar las pruebas de placebo

\begin{tabular}{|c|c|c|c|c|c|c|}
\hline $\begin{array}{c}\text { Variable } \\
\text { dependiente }\end{array}$ & Etapa & Año & $\begin{array}{c}\text { Cambio } \\
\text { anual }\end{array}$ & $\begin{array}{l}\text { Valores } p \text { no } \\
\text { restringidos }\end{array}$ & $\begin{array}{l}\text { Valores } p \\
\text { ajustados no } \\
\text { restringidos }\end{array}$ & $\begin{array}{c}\text { Significancia } \\
\text { estadística } \\
\text { de valores } \\
\text { p ajustados } \\
\left(1 \%==^{* * *}, 5 \% \%^{* *} \text {, }\right. \\
\left.10 \%{ }^{*}\right)\end{array}$ \\
\hline \multirow{13}{*}{$\begin{array}{l}\text { Índice de } \\
\text { corrupción } \\
\text { política }\end{array}$} & \multirow{2}{*}{ Compromiso } & 2005 & 0 & 0,69 & 0,32 & no significativo \\
\hline & & 2006 & 0,04 & 0,15 & 0,09 & * \\
\hline & \multirow{5}{*}{ Candidatura } & 2007 & 0,04 & 0,18 & 0,09 & * \\
\hline & & 2008 & 0,05 & 0,2 & 0,11 & no significativo \\
\hline & & 2009 & 0,05 & 0,21 & 0,11 & no significativo \\
\hline & & 2010 & 0,09 & 0,13 & 0,1 & * \\
\hline & & 2011 & 0,04 & 0,36 & 0,16 & no significativo \\
\hline & \multirow{6}{*}{ Cumplimiento } & 2012 & 0,04 & 0,35 & 0,15 & no significativo \\
\hline & & 2013 & 0,12 & 0,13 & 0,05 & ** \\
\hline & & 2014 & 0,12 & 0,13 & 0,05 & ** \\
\hline & & 2015 & $-0,01$ & 0,88 & 0,45 & no significativo \\
\hline & & 2016 & $-0,02$ & 0,7 & 0,31 & no significativo \\
\hline & & 2017 & 0 & 0,96 & 0,64 & no significativo \\
\hline
\end{tabular}

Fuente: adaptado de VDem (2019) y Banco Mundial (2019) utilizando Stata.

De manera más específica, la figura 2 visualmente indica que, luego de la intervención de la IETI, el índice de corrupción política para Perú se mueve por encima de la unidad sintética (línea punteada) entre 2005 y 2015, lo cual indicaría que la percepción de corrupción no se ha reducido en este período. Asimismo, dentro de este período existen años (2005, 2008 y 2009, 2011, 2012 y 2015) en los cuales no hay significancias estadísticas (los valores $p$ son superiores al $10 \%$ ), mostrando también que no hay un efecto de la EITI en los niveles transparencia (figura 3). Más en detalle, se puede ver que en 2006 y 2007, en el Índice de Corrupción Política del Perú el desvío 
es estadísticamente significativo de su unidad sintética en la etapa de compromiso y candidatura, con un cambio anual mínimo de la brecha entre las dos unidades de 0,04 respectivamente al 10\% de significancia. Igualmente, en la tabla 1 se puede ver que alrededor de la etapa de cumplimiento, esta desviación estadística significativa se da en 2010 (0,09 cambio anual al 10\% de significancia estadística) y entre 2013 y 2014 (0,12 cambio anual al 5\% de significancia estadística), en donde el índice de corrupción política de Perú fluctúa por encima de la unidad sintética. Finalmente, entre 2015 a 2017, el índice tiende a reducir, pero no tiene significancia estadística.

Figura 2

Índice de corrupción política en el Perú

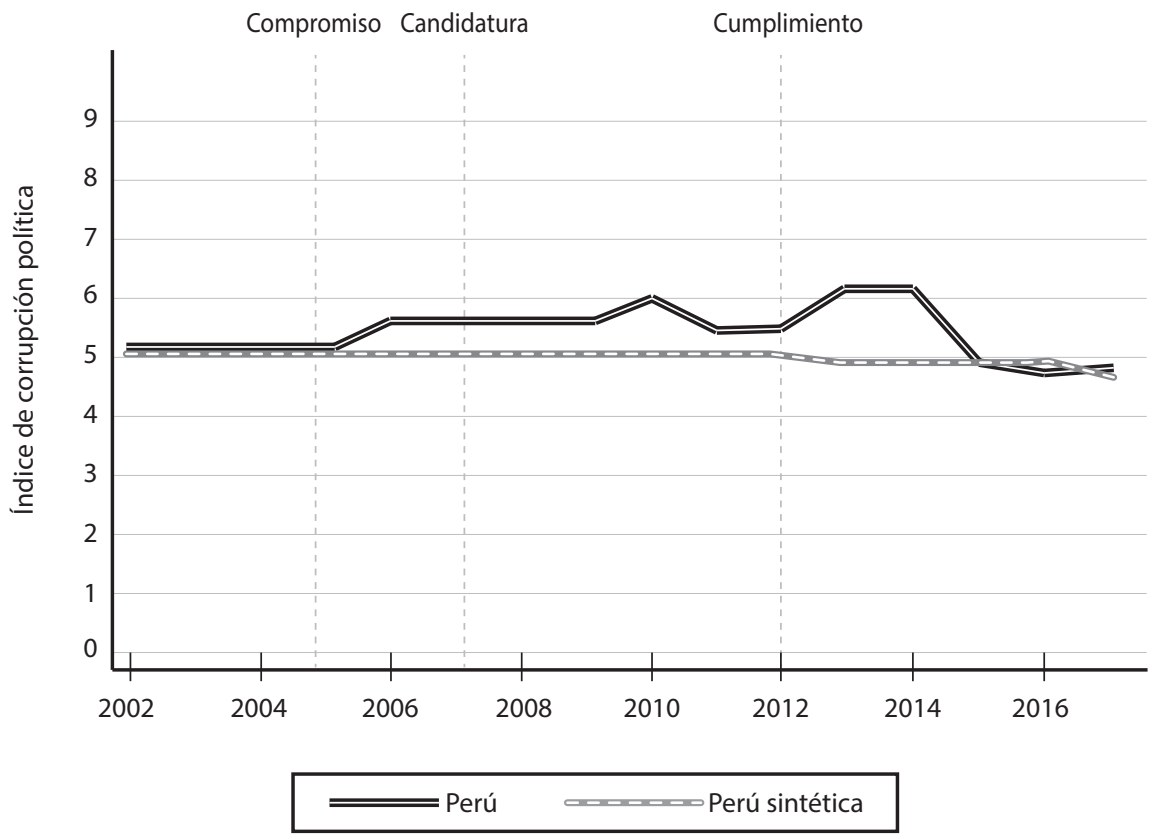

Fuente: VDem (2019) y Banco Mundial (2019).

Estimación del autor utilizando Stata. 
Figura 3

Valores $p$ ajustados

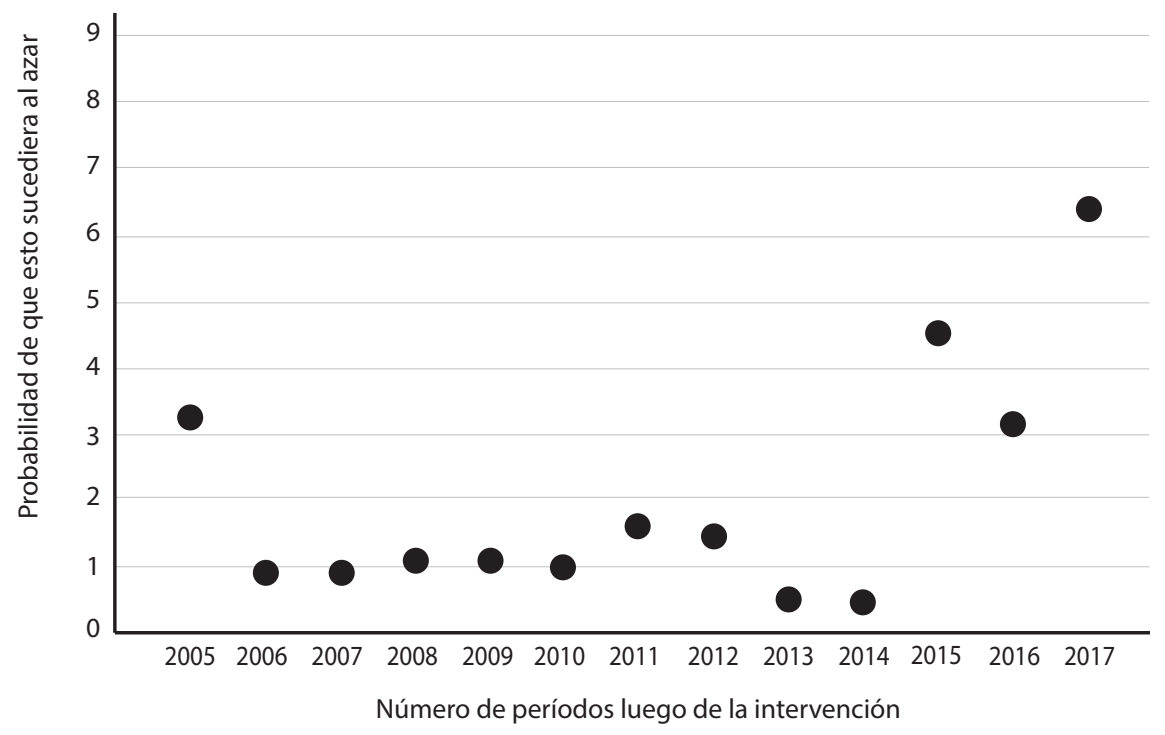

Fuente: VDem (2019) y Banco Mundial (2019).

Estimación del autor utilizando Stata.

\section{Discusión y análisis}

El índice de Corrupción Política comprende diferentes niveles, esta percepción de corrupción aumentada puede haber estado influida por los diferentes escándalos de corrupción en el país, especialmente a nivel político en el sector extractivo, mermando la intervención de la IETI. Durante la intervención de la EITI se han producido algunos casos de corrupción en Perú como el caso de la compañía estatal de petróleo Petroperú. En 2005, esta compañía estuvo involucrada en la modernización del proyecto Refinería Talara, cuestionada por su excesivo sobreprecio, así como la falta de transparencia en el proceso de concesión (Manco 2010). Posteriormente, entre 
2008 y 2011 se dio el caso de corrupción de los Petroaudios, donde se revelaron declaraciones sobre pago de sobornos a empleados de Petroperú para favorecer a la compañía petrolera Discover Noruega con el fin de obtener contratos de exploración de petróleo submarino y campos de gas (De Cuello Blanco 2012).

Otro caso de corrupción es el de la empresa Odebrecht, descubierto en 2016, quien pagó alrededor de USD 29 millones en sobornos a funcionarios públicos peruanos entre 2005 y 2014 con el propósito de obtener varios contratos que sumaron USD 12,5 mil millones (Faiola 2018).

Adicionalmente, Perú se caracteriza por tener serios problemas de conflictos en donde la actividad minera está presente. Sin embargo, los conflictos mineros no son los únicos problemas, sino también la falta de transparencia. En este sentido, la inclusión de la EITI para apaciguar los conflictos, mediante la incorporación de la sociedad civil para el correcto funcionamiento del sector extractivo y beneficio de las comunidades, no estaría bien dirigida. Por ejemplo, en 2012, la minera Antamina causó la ruptura del oleoducto mineral que afectó a las poblaciones cercanas y los ríos. Además, esta empresa estuvo involucrada en transacciones ilegales de tierras y reasignaciones injustas de las comunidades. En 2013, Antamina también fue sospechoso de colusión en una región altamente vulnerable a prácticas corruptas debido a la actividad minera (Quispe, Cárdenas y Torrico 2018). La minera Tintaya, también en 2012, provocó disturbios y una declaración de estado de emergencia debido a la expansión de sus operaciones mineras. En tanto, en Camisea — proyecto de hidrocarburos-, entre 2005 y 2009, se cuestionó porque la empresa negoció con México mayores exportaciones de gas que dejaron con escasez a la demanda nacional (Sanborn y Dammert Bello 2013). En este sentido, es evidente que la política de transparencia del EITI es limitada para disuadir casos de corrupción.

Por otro lado, analizando los reportes de la EITI Perú (2004-2007, 20082010, 2011-2012, 2013, 2014) se identifican inconsistencias en la conciliación de los valores reportados por las compañías y los del gobierno. Si bien las inconsistencias no son materiales (entre 0,001 a $17 \%$ en los diferentes informes), la participación de las empresas en los reportes EITI no son al $100 \%$ debido a su carácter de voluntariedad de participación (95\% hidrocarburos y $85 \%$ minería), lo cual evidencia el limitado alcance de la EITI 
a todas las compañías del sector extractivo en Perú (EITI Perú 2009; EITI Perú 2011; EITI Perú 2014a; EITI Perú 2014b; EITI Perú 2014c). Puesto que muchas mineras no se encuentran en el estudio no es posible evidenciar sus ingresos y cómo se traducen a las localidades. Igualmente, en los reportes no se incluían en un principio las tasas regionales y municipales y otros valores relacionados con la contribución minera. La Secretaría de la EITI acepta que no pueden participar todas las compañías por lo que el concepto de materialidad no es consensuado.

Perú es el primer país en la región en extender y descentralizar la aplicación de la EITI a dos municipalidades: Moquegua y Piura. Moquegua es una región caracterizada por tener dentro de las actividades principales la extracción de petróleo, gas, minerales y servicios relacionados. El informe de la EITI Perú Moquegua 2012-2013 evidencia la falta de conexión entre los ingresos mineros y la transparencia del uso de estos fondos, en una porción de las declaraciones de ingresos se indica un ítem "sin productos", sin distinguir cómo se ha usado o cuáles han sido los productos concretos. La EITI también menciona la ausencia de un sistema eficiente de monitoreo de la distribución de ingresos a los diferentes niveles de gobierno (EITI Perú 2016b). En el informe EITI Perú Piura 2012-2013, referente a las áreas de Talara y Castile, se realizaron las conciliaciones de ingresos sin encontrarse diferencias, sin embargo, hay discrepancias en los montos de derechos de validación. Se evidencia también débiles mecanismos de rendición de cuentas, enfocados en los ingresos en lugar de los resultados (EITI Perú 2016a). Si bien la EITI se ha expandido a estas dos regiones, es importante mencionar que hay otras regiones en donde hay también una gran concentración de minerales e hidrocarburos como son: Ancash, Cajamarca, Tumbes y Loreto (EITI Perú 2018).

Se reconoce ampliamente que la gobernanza en los niveles subnacionales de gobierno es a menudo débil; la corrupción es generalizada y la capacidad administrativa y de gestión de proyectos es baja. La implementación regional de la EITI en Perú ha sido lenta y con resultados limitados, sin mejorar la participación de los gobiernos locales que tienen mayor incidencia en la participación civil. Una mayor participación significa mejorar la transparencia, la rendición de cuentas y mejores políticas para evitar la corrupción. Autores como Dykstra (2011), Aaronson (2011), Kasekende, Abuka y Sarr (2016), Lujala, Aas Rustad y Le Billon (2017), y Öge (2016) coinciden con estas me- 
didas de anticorrupción. No obstante, las partes interesadas en las regiones piloto han acogido la implementación de la EITI como una plataforma para discutir los impactos de la industria local y asegurar una mejor utilización de los ingresos.

En este contexto, los escándalos de corrupción, las inconsistencias encontradas en los reportes EITI nacionales y locales, así como la insuficiente participación de la sociedad civil, explicarían el efecto nulo de la EITI en la reducción de la corrupción (EITI Perú 2016c).

\section{Conclusiones}

A través de los años, la teoría de la maldición de recursos ha ido evolucionando, manifestando la estrecha relación entre la corrupción y el crecimiento económico en los países ricos en recursos naturales. Con base en esta teoría se han implementado iniciativas de transparencia, como la EITI, para mejorar la gobernanza, institucionalidad, transparencia y rendición de cuentas que permitan generar un crecimiento económico deseado. La EITI, basada en estos principios, ha influido para que los países alrededor del mundo se unan a la iniciativa. De igual manera, cada vez más estudios cualitativos y cuantitativos se han realizado para evaluar el efecto que la EITI ha tenido en diferentes países, y pocos de ellos son en casos individuales. Es así que el análisis del primer país en unirse a la iniciativa en la región es relevante ya que da una visión general del funcionamiento de la EITI en las diferentes etapas de implementación, en el período 2002 a 2017. Los resultados de la investigación muestran que la EITI no ha tenido efecto en la reducción de la percepción de corrupción en Perú.

Más en detalle podemos decir que el Índice de Corrupción Política de Perú crece luego de la intervención de la EITI, es decir, la EITI no ha tenido un efecto en la transparencia de Perú. La diferencia entre este índice y su unidad sintética es mínima, pero significativa en la etapa de candidatura y alrededor de la etapa de cumplimiento. Este nulo efecto de la EITI podría explicarse por los constantes casos de corrupción en el país, en el sector extractivo, por la limitada participación de la sociedad civil a nivel local y 
la poca influencia de los reportes de la EITI, lo cual estaría en detrimento de su accionar.

El uso de índices generales de corrupción, y no específicos al sector, podría limitar el análisis. La lucha contra la corrupción requiere el compromiso del gobierno y la implementación de medidas complementarias a nivel nacional en todos los sectores, tales como planes anticorrupción con innovaciones tecnológicas que permitan a gente de partes remotas reportar actos de corrupción. Adicionalmente, la legislación en materia de corrupción debe establecer que las personas denunciantes tengan las garantías para que no se tomen represalias en su contra. Asimismo, los gobiernos deben garantizar la participación de la sociedad civil para mejorar la transparencia, la rendición de cuentas y la formulación de políticas de anticorrupción.

Finalmente, los resultados de la MCS para Perú, en conjunto con los casos de corrupción presentados tanto a nivel nacional como local, muestran que la EITI, como un mecanismo de transparencia ha fallado en reducir la percepción de corrupción. Mientras la EITI funcionaba, los casos de corrupción en el sector extractivo tenían lugar. Se debe reforzar el papel de la EITI y su grupo de multipartícipes en el seguimiento de los hallazgos de los informes, fomentar la participación local a través de los municipios y expandir su accionar a otros niveles locales en donde hay también prominente actividad extractiva. Se recomienda realizar otros análisis en otros países del mundo con niveles similares de corrupción y del sector extractivo para poder generar análisis comparativos que permitan corroborar este resultado.

\section{Referencias}

Aaronson, Susan Ariel. 2011. "Limited Partnership: Business, Government, Civil Society and the Public in the Extractive Industries Transparency Initiative (EITI)". Public Administration \& Development 31 (1): 49-50. https://doi.org/10.1002/pad.588.

Abadie, Alberto, Alexis Diamond y Jens Hainmueller. 2010. "Synthetic Control Methods for Comparative Case Studies: Estimating the Effect of California's Tobacco Control Program". Journal of the American Statistical Association 105 (490): 493-505. https://doi. org/10.1198/jasa.2009.ap08746.

---. 2015. "Comparative Politics and the Synthetic Control Method". American Journal of Political Science 59 (2): 495-510. https://stanford.io/3hhJ5ru. 
Abadie, Alberto, y Javier Gardeazabal. 2003. "The Economic Costs of Conflict: A Case Study of the Basque Country". American Economic Review 93 (1): 113-132. https:// doi.org/10.1257/000282803321455188.

Ades, Alberto, y Rafael Di Tella. 1999. "Rents, Competition, and Corruption”. American Economic Review 89 (4): 982-993. https://doi.org/10.1257/aer.89.4.982.

Ali, Abdiweli, y Hodan Said Isse. 2002. "Determinants of Economic Corruption: A Cross-Country Comparison”. Cato 22: 440-449. https://bit.ly/3qLcEoE.

Andersen, Jørgen J., y Michael L. Ross. 2014. "The Big Oil Change: A Closer Look at the Haber-Menaldo Analysis”. Comparative Political Studies 47 (7): 993-1021. https://doi. org/10.1177/0010414013488557.

Aslaksen, Silje. 2010. “Oil and Democracy: More Than a Cross-Country Correlation?”. Journal of Peace Research 47 (4): 421-431. https://doi.org/10.1177/0022343310368348.

Ata, Yilmaz, y Akif Arvas. 2011. "Determinants of Economic Corruption: A Cross-Country Data Analysis". International Journal of Business and Social Science 2 (13): 161-169. https://doi.org/10.1.1.463.1061.

Auty, Richard M. 1994. "Industrial Policy Reform in Six Large Newly Industrializing Countries: The Resource Curse Thesis". World Development 22 (1): 11-26. https://bit. ly/36cWPNY.

Bolaños, Rolando. 2017. "Reseña histórica de la exploración por petróleo en las cuencas costeras del Perú". Boletín de la Sociedad Geológica del Perú 112: 1-13.

Boschini, Anne D., Jan Pettersson y Jesper Roine. 2007. "Resource Curse or Not: A Question of Appropriability". Scandinavian Journal of Economics 109 (3): 593-617. https:// doi.org/10.1111/j.1467-9442.2007.00509.x.

Brunetti, Aymo, y Beatrice Weder. 2003. “A Free Press Is Bad News for Corruption”. Journal of Public Economics 87 (7-8): 1801-1824. https://doi.org/10.1016/S00472727(01)00186-4.

Calder, Fanny, y Malaika Culverwell. 2005. "Following up the World Summit on Sustainable Development Commitments on Corporate Social Responsibility”. Londres: Chatham House. https://bit.ly/2TslzPu.

Correa, Rafael. 2012. Ecuador: de banana republic a la no república. Bogotá: Debate.

Collier, Paul. 2008. "Global Policies for the Bottom Billion: A Progressive Agenda for Global Action”. Policy Network 1 (1): 141-149. https://doi.org/10.1.1.459.684.

Collier, Paul, y Anke Hoeffler. 1998. "On Economic Causes of Civil War”. Oxford Economic Papers 50 (4): 563-573. https://doi.org/10.1093/oep/50.4.563.

Collier, Paul, Anke Hoeffler y Dominic Rohner. 2009. "Beyond Greed and Grievance: Feasibility and Civil War”. Oxford Economic Papers 61 (1): 1-27. https://doi.org/10.1093/oep/gpn029.

Corrigan, Caitlin. 2017. "The Effects of Increased Revenue Transparency in the Extractives Sector: The Case of the Extractive Industries Transparency Initiative". The Extractive Industries and Society 4 (4): 779-787. https://doi.org/10.1016/j.exis.2017.03.004.

Dammert Lira, Alfredo, y Fiorella Molinelli Aristondo. 2007. Panorama de la minería en el Perú. Lima: OSINERGIM. 
De Cuello Blanco. 2012. "La corrupción en el Perú: últimos veinte años”. Accedido septiembre de 2019. https://bit.ly/3qMtaEZ.

Del Castillo Durand, Mirtha Lorena. 2015. “Análisis de la efectividad de la mesa de diálogo de responsabilidad social como promotora del desarrollo de la provincia de Talara, Piura, Perú (período 2012-2013)”. Tesis de grado, Pontificia Universidad Católica del Perú, Lima. https://bit.ly/3hTYYop.

Dykstra, Page. 2011. "Learning from Success and Challenges". EITI 2011 Briefing. Accedido abril 2021. https://bit.ly/36d0XgY.

Eguren, Mariana, Carolina De Belaunde y Ana Luisa Burga. 2005. Huancavelica cuenta: temas de historia huancavelicana contados por sus protagonistas. Lima: Instituto de Estudios Peruanos.

Elbahnasawy, Nasr G., y Charles F. Revier. 2012. "The Determinants of Corruption: Cross-Country-Panel-Data Analysis". The Developing Economies 50 (4): 311-333. https:// doi.org/10.1111/j.1746-1049.2012.00177.x.

Etter, Luca. 2012. Can Transparency Reduce Corruption? Evidence from Firms in Peru and Mali on the Impact of the Extractive Industries Transparency Initiative (EITI) on Corruption. Tesis de Posgrado. Georgetown University, Washington D.C. http://hdl.handle. net/10822/557839.

Extractive Industries Transparency Initiative of Peru (EITI Perú). 2009. Final Report "Consulting Service for Preparation of the EITI-Peru National Reconciliation Study 20042007”. Lima: EITI Perú.

---. 2011. Final Report. Second National Reconciliation Study of the Extractive Industries Transparency Initiative (EITI) in Peru (2008-2010)-Final Version Consultancy for the EITI Peru Multi-Sector Working Committee. Lima: EITI Perú.

---.2014a. Final Report. Third National Reconciliation Study of the Extractive Industries Transparency Initiative (EITI) in Peru (2011-2012)-Final Version. Lima: EITI Perú.

---. 2014b. Final Report. Forth National Reconciliation Study of the Extractive Industries Transparency Initiative (EITI) in Peru (2013)-Final Version Consultancy for the EITI Peru Multi-Sector Working Committee. Lima: EITI Perú.

---. 2014c. Fifth National Reconciliation Study of the Extractive Industries Transparency Initiative (EITI) in Peru (2014)-Final Version Consultancy for the EITI Peru Multi-Sector Working Committee. Lima: EITI Perú.

---. 2016a. Piura 2012-2013 Sub-national EITI Report. Report prepared for the EITI Peru Permanent Multisectoral Commission, in coordination with the EITI Piura Regional Commission. Lima: EITI Perú-Piura.

---. 2016b. Moquegua 2012-2013 Sub-national EITI Report. Report prepared for the EITI Peru Permanent Multisectoral Commission, in coordination with the EITI Moquegua Regional Commission. Lima: EITI Perú-Moquegua.

---.2016c. Reporte de validación de Perú 2016. Lima: EITI Perú. 
---.2018. Séptimo informe nacional de transparencia de las industrias extractivas (Séptimo estudio de conciliación nacional-EITI Perú) Periodos 2017 y 2018. Lima: EITI Perú.

Faiola, Anthony. 2018. "The Corruption Scandal Started in Brazil. Now it's Wreaking Havoc in Peru". The Washington Post. Accedido septiembre de 2019. https://wapo.st/2QbZtz6.

Galeano, Eduardo. 2014. Las venas abiertas de América Latina. Bogotá. Siglo XXI.

Galiani, Sebastian, y Brian Quistorff. 2017. "The Synth_Runner Package: Utilities to Automate Synthetic Control Estimation Using Synth”. The Stata Journal (17) 4: 834-849. https://doi. org/10.1177/1536867X1801700404.

Gilberthorpe, Emma, y Elissaios Papyrakis. 2015. "The Extractive Industries and Development: The Resource Curse at the Micro, Meso and Macro Levels". The Extractive Industries and Society 2 (2): 381-390. https://doi.org/10.1016/j.exis.2015.02.008.

Gillies, Alexandra, y Antoine Heuty. 2011. "Does Transparency Work-The Challenges of Measurement and Effectiveness In Resource-Rich Countries". Yale J. Int'l Aff. (6): 21-25. https://bit.ly/3odShiD.

Gunesch, Konrad. 2018. "The Natural Resource Curse: A Socioeconomic and Sociopolitical Analysis of Causes and Symptoms Combined with Macroeconomic Solution Suggestions for International Development Policy and Practice". Review of Socio-Economic Perspectives 3 (1): 73-95. https://doi.org/10.19275/RSEP044.

Hoinathy, Remadji, y Babett Jánszky. 2017. "The Extractive Industries Transparency Initiative (EITI): The Latest Attempt at Governing The Extractive Industries In Chad". The Extractive Industries and Society 4 (4): 825-832. https://doi.org/10.1016/j.exis.2017.11.004.

Jain, Arvind. 2001. "Corruption: A Review". Journal of Economic Surveys 15 (1): 71-121. https:// doi.org/10.1111/1467-6419.00133.

Karl, Terry Lynn. 1997. The Paradox of Plenty: Oil Booms and Petro-States. Oakland: University of California Press.

Kasekende, Elizabeth, Charles Abuka y Mare Sarr. 2016. "Extractive Industries and Corruption: Investigating the Effectiveness of EITI as A Scrutiny Mechanism". Resources Policy (48): 117-128. https://doi.org/10.1016/j.resourpol.2016.03.002.

Katzarova, Elitza. 2018. The Social Construction of Global Corruption: From Utopia to Neoliberalism. Basingstoke: Palgrave Macmillan.

Kolstad, Ivar. 2009. “The Resource Curse: Which Institutions Matter?". Applied Economics Letters 16 (4): 439-442. https://doi.org/10.1080/17446540802167339.

Kolstad, Ivar, y Arne Wiig. 2009. "Is Transparency the Key to Reducing Corruption In Resource-Rich Countries?”. World Development 37 (3): 521-532. https://doi.org/10.1016/j. worlddev.2008.07.002.

Krueger, Anne O. 1974. "The Political Economy of the Rent-Seeking Society". The American Economic Review 64 (3): 291-303. https://www.jstor.org/stable/1808883.

Lewis, W. Arthur. 2013. Theory of Economic Growth. Cambridge: Routledge. 
Lujala, Päivi, Siri Aas Rustad y Philippe Le Billon. 2017. "Has the EITI Been Successful? Reviewing Evaluations of the Extractive Industries Transparency Initiative". U4Brief. Accedido abril de 2020. http://hdl.handle.net/11250/2475408.

Manco, Jorge. 2010. "PetroPerú-Talara: en la Mira de la corrupción (II)" América Latina en Movimiento. Accedido septiembre de 2020. https://www.alainet.org/es/active/37354.

Manzano, Osmel, y Roberto Rigobon. 2001. "Resource Curse or Debt Overhang?". National Bureau of Economic Research. Accedido septiembre de 2020. 10.3386/w8390.

Ministerio de Energía y Minas del Perú (MINEM). 2021a. "Boletín estadístico minero 012021”. Accedido marzo de 2021. https://bit.ly/3wkTWoM.

---. 2021b. "Informe estadístico Upstream Downstream". Accedido marzo de 2021. https://bit. ly/36hA2Ax.

Öge, Kerem. 2016. "Which Transparency Matters? Compliance with Anti-Corruption Efforts in Extractive Industries". Resources Policy 49: 41-50. https://doi.org/10.1016/j.resourpol.2016.04.001.

Organismo Supervisor de la Inversión en Energía y Minería (OSINERGMIN). 2019. "Reporte de análisis económico sectorial sector minería, relación actual y futura entre el sector minero y el sector eléctrico", año 8, No. 12, diciembre 2019. Lima: OSINERGMIN. https:// bit.ly $/ 3 \mathrm{w} 35 \mathrm{sWh}$.

Orogun, Paul S. 2010. "Resource Control, Revenue Allocation and Petroleum Politics in Nigeria: The Niger Delta Question”. GeoJournal 75 (5): 459-507. https://doi.org/10.1007/ s10708-009-9320-7.

Papyrakis, Elissaios. 2017. "The Resource Curse-What Have We Learned from Two Decades of Intensive Research: Introduction to the Special Issue". The Journal of Development Studies 53 (2): 175-185. https://doi.org/10.1080/00220388.2016.1160070.

Papyrakis, Elissaios, Matthias Rieger y Emma Gilberthorpe. 2017. "Corruption and the Extractive Industries Transparency Initiative”. The Journal of Development Studies 53 (2): 295-309. https://doi.org/10.1080/00220388.2016.1160065.

Park, Hoon. 2003. "Determinants of Corruption: A Cross-National Analysis". Multinational Business Review 11 (2): 29-48. https://doi.org/10.1108/1525383X200300010.

Pegg, Scott. 2006. "Mining and Poverty Reduction: Transforming Rhetoric into Reality". Journal of Cleaner Production 14 (3-4): 376-387. https://doi.org/10.1016/j.jclepro.2004.06.006.

Persson, Torsten, Guido Tabellini y Francesco Trebbi. 2003. "Electoral Rules and Corruption". Journal of the European Economic Association 1 (4): 958-989. https://doi.org/10.1 $162 / 154247603322493203$.

Quiroz, Alfonso W. 2014. Historia de la corrupción en el Perú. Lima: Instituto de Estudios Peruanos.

Quispe, Anthony, Jackeline Cárdenas y Gonzalo Torrico. 2018. "Southern, Antamina, Doe Run y otras mineras en el ojo de la sunat por festival de gastos para burlar impuestos". Accedido enero 2020. https://bit.ly/2QcYyyn. 
Ravat, Anwar, y Andre Ufer. 2010. "Toward Strengthened EITI Reporting: Summary Report and Recommendations". Accedido noviembre de 2020. http://hdl.handle.net/10986/18281.

Ross, Michael L. 2001. “Does Oil Hinder Democracy?”. World Politics 8: 325-361. https:// bit.ly/3hHKve3.

Sanborn, Cynthia, y Juan Luis Dammert Bello. 2013. "Perú: extracción de recursos naturales, desarrollo económico e inclusión social". Accedido abril de 2021. https://repositorio. up.edu.pe/handle/11354/1103.

Sarmidi, Tamat, Siong Hook Law y Yaghoob Jafari. 2014. "Resource Curse: New Evidence on the Role of Institutions". International Economic Journal 28 (1): 191-206. https://doi. org/10.1080/10168737.2013.787110.

Serra, Danila. 2006. "Empirical Determinants of Corruption: A Sensitivity Analysis". Public Choice 126 (1): 225-256. https://bit.ly/2UrrNPG.

Shabbir, Ghulam, y Mumtaz Anwar. 2007. "Determinants of Corruption in Developing Countries". The Pakistan Development Review 46 (4): 751-764. www.jstor.org/stable/41261194.

Sovacool, Benjamin K., Götz Walter, Thijs Van de Graaf y Nathan Andrews. 2016. "Energy Governance, Transnational Rules, and the Resource Curse: Exploring the Effectiveness of the Extractive Industries Transparency Initiative (EITI)". World Development (83): 179192. https://doi.org/10.1016/j.worlddev.2016.01.021.

Sovacool, Benjamin K., y Nathan Andrews. 2015. "Does Transparency Matter? Evaluating the Governance Impacts of the Extractive Industries Transparency Initiative (EITI) in Azerbaijan and Liberia". Resources Policy (45): 183-192. https://doi.org/10.1016/j.resourpol.2015.04.003.

Stevens, Paul, y Evelyn Dietsche. 2008. "Resource Curse: An Analysis of Causes, Experiences and Possible Ways Forward”. Energy Policy 36 (1): 56-65. https://doi.org/10.1016/j. enpol.2007.10.003.

Treisman, Daniel. 2000. "The Causes of Corruption: A Cross-National Study". Journal of Public Economics 76 (3): 399-457. https://doi.org/10.1016/S0047-2727(99)00092-4.

Tsui, Kevin K. 2011. "More Oil, Less Democracy: Evidence from Worldwide Crude Oil Discoveries". The Economic Journal 121 (551): 89-115. https://doi.org/10.1111/j.14680297.2009.02327.x.

Van Alstine, James. 2017. "Critical Reflections on 15 Years of the Extractive Industries Transparency Initiative (EITI)". The Extractive Industries and Society 4 (4): 766-770. https:// doi.org/10.1016/j.exis.2017.10.010.

Varieties of Democracy (V-Dem). 2019. "Data of Varieties of Democracy." Varieties of Democracy. Accedido marzo 2021. https://www.v-dem.net.

Vieyra, Juan, y Malaika Masson. 2014. "Transparent Governance in an Age of Abundance: Experiences from the Extractive Industries in Latin America and the Caribbean". Accedido agosto de 2020. https://bit.ly/36gARJW. 
Villar, Paul Fenton, y Elissaios Papyrakis. 2017. "Evaluating the Impact of the Extractive Industries Transparency Initiative (EITI) on Corruption in Zambia". The Extractive Industries and Society 4 (4): 795-805. https://doi.org/10.1016/j.exis.2017.01.009.

Warf, Barney, y Sheridan Stewart. 2016. "Latin American Corruption in Geographic Perspective". Journal of Latin American Geography 15 (1): 133-155. https://bit.ly/36jbNCd.

Watkins, Melville H. 1963. "A Staple Theory of Economic Growth". The Canadian Journal of Economics and Political Science 29 (2): 141-158. https://www.jstor.org/stable/139461.

Weszkalnys, Gisa. 2011. "Cursed Resources, Or Articulations of Economic Theory in the Gulf of Guinea”. Economy and Society 40 (3): 345-372. https://bit.ly/2UkjAgh. 


\section{Anexos}

\section{Anexo 1 \\ Descripción de las variables}

\begin{tabular}{|c|c|c|}
\hline Nombre de la variable & Descripción & Fuente \\
\hline \multicolumn{3}{|l|}{ Variable de resultado } \\
\hline Corrupción política & $\begin{array}{l}\text { El índice de corrupción incluye medidas de seis tipos distin- } \\
\text { tos de corrupción que cubren diferentes áreas y niveles del } \\
\text { ámbito de la política, distinguiendo entre corrupción ejecu- } \\
\text { tiva, legislativa y judicial. Dentro del ámbito ejecutivo, las } \\
\text { medidas también distinguen entre la corrupción principal- } \\
\text { mente relacionada con el soborno y por malversación. Fi- } \\
\text { nalmente, diferencian entre la corrupción en los escalones } \\
\text { más altos del ejecutivo a nivel de gobernantes / gabinete, } \\
\text { por un lado, y en el sector público en general, por el otro. } \\
\text { Por lo tanto, las medidas aprovechan varios tipos distingui- } \\
\text { dos de corrupción: tanto "pequeña" como "grande"; tanto el } \\
\text { soborno como el robo; tanto la corrupción tiene como obje- } \\
\text { tivo e influye en la elaboración de leyes y la que afecta su } \\
\text { implementación (altos índices = más corrupción política). } \\
\text { Escala } 0 \text { (más baja) a } 1 \text { (más alta). }\end{array}$ & VDem \\
\hline \multicolumn{3}{|c|}{ Variables predictoras económicas } \\
\hline Logaritmo del PIB & $\begin{array}{l}\text { PIB en logaritmo para limitar grandes cantidades (USD } \\
\text { actuales). }\end{array}$ & BM \\
\hline Crecimiento del PIB & Crecimiento del PIB (\% anual). & BM \\
\hline $\begin{array}{l}\text { Logaritmo del PIB per } \\
\text { cápita }\end{array}$ & $\begin{array}{l}\text { PIB per cápita en logaritmo para limitar grandes cantidades } \\
\text { (USD actuales). }\end{array}$ & BM \\
\hline Comercio* & $\begin{array}{l}\text { Comercio (\% del PIB). El comercio es la suma de las ex- } \\
\text { portaciones e importaciones de bienes y servicios medidos } \\
\text { como porcentaje del producto interno bruto. }\end{array}$ & BM \\
\hline Rentas minerales & $\begin{array}{l}\text { Es el valor agregado de las rentas minerales, las rentas del } \\
\text { carbón, las rentas del gas y las rentas del petróleo (\% del PIB). }\end{array}$ & BM \\
\hline \multicolumn{3}{|c|}{ Variables predictoras sociales } \\
\hline Logaritmo de población & Población total en logaritmo para limitar un gran número. & BM \\
\hline Tasa de natalidad & $\begin{array}{l}\text { Tasa de natalidad, bruta (por cada } 1000 \text { personas). Núme- } \\
\text { ro de nacidos vivos ocurridos durante el año, por cada } 1000 \\
\text { habitantes estimados. }\end{array}$ & BM \\
\hline
\end{tabular}

* No se usó Trinidad y Tobago debido a la ausencia de observaciones. 


\begin{tabular}{|c|c|c|}
\hline Tasa de mortalidad & $\begin{array}{l}\text { Tasa de mortalidad, bruta (por cada } 1000 \text { personas). } \\
\text { Número de defunciones ocurridas durante el año, por } 1000 \\
\text { habitantes estimados. }\end{array}$ & BM \\
\hline $\begin{array}{l}\text { Servicios básicos de } \\
\text { agua potable }\end{array}$ & $\begin{array}{l}\text { Personas que utilizan al menos los servicios básicos de } \\
\text { agua potable (\% de la población). }\end{array}$ & BM \\
\hline $\begin{array}{l}\text { Servicios de sanea- } \\
\text { miento básico }\end{array}$ & $\begin{array}{l}\text { Personas que utilizan al menos los servicios básicos de } \\
\text { saneamiento (\% de la población). }\end{array}$ & BM \\
\hline Acceso a electricidad & Acceso a la electricidad (\% de la población). & $\mathrm{BM}$ \\
\hline $\begin{array}{l}\text { Tasa de fecundidad } \\
\text { adolescente }\end{array}$ & $\begin{array}{l}\text { Tasa de fecundidad adolescente (nacimientos por cada } \\
1000 \text { mujeres de } 15 \text { a } 19 \text { años). }\end{array}$ & BM \\
\hline $\begin{array}{l}\text { Esperanza de vida al } \\
\text { nacer, mujer }\end{array}$ & $\begin{array}{l}\text { Esperanza de vida al nacer, mujer (años). El número de } \\
\text { años que viviría un recién nacido si prevalecieran los pa- } \\
\text { trones de mortalidad en el momento de su nacimiento. }\end{array}$ & BM \\
\hline $\begin{array}{l}\text { Esperanza de vida al } \\
\text { nacer, hombre }\end{array}$ & $\begin{array}{l}\text { Esperanza de vida al nacer, varones (años). El número } \\
\text { de años que viviría un recién nacido si prevalecieran los } \\
\text { patrones de mortalidad en el momento de su nacimiento. }\end{array}$ & BM \\
\hline $\begin{array}{l}\text { Tasa de mortalidad in- } \\
\text { fantil }\end{array}$ & $\begin{array}{l}\text { Tasa de mortalidad infantil (por cada } 1000 \text { nacidos vivos). } \\
\text { Número de muertes de lactantes menores de un año por } \\
\text { cada } 1000 \text { nacidos vivos. }\end{array}$ & BM \\
\hline $\begin{array}{l}\text { Participación de la fuer- } \\
\text { za laboral }\end{array}$ & $\begin{array}{l}\text { Tasa de participación en la fuerza laboral, total (\% de la } \\
\text { población total de } 15 \text { años o más) (estimación modelada de } \\
\text { la OIT). Proporción de la población de } 15 \text { años o más que } \\
\text { es económicamente activa. }\end{array}$ & BM \\
\hline Desempleo & $\begin{array}{l}\text { Desempleo, total (\% de la fuerza laboral total) (estimación } \\
\text { modelada de la OIT). Proporción de la población activa que } \\
\text { no tiene trabajo pero está disponible y busca empleo. }\end{array}$ & BM \\
\hline Empleo vulnerable & $\begin{array}{l}\text { Empleo vulnerable, total (\% del empleo total) (estimación } \\
\text { modelada de la OIT). }\end{array}$ & BM \\
\hline $\begin{array}{l}\text { Relación empleo / po- } \\
\text { blación, mujeres }\end{array}$ & $\begin{array}{l}\text { Relación empleo / población, mayores de } 15 \text { años, mujeres } \\
\text { (\%) (estimación modelada de la OIT). Proporción de mu- } \\
\text { jeres empleadas en un país. }\end{array}$ & BM \\
\hline $\begin{array}{l}\text { Relación empleo / po- } \\
\text { blación, hombres }\end{array}$ & $\begin{array}{l}\text { Relación empleo / población, mayores de } 15 \text { años, hom- } \\
\text { bres (\%) (estimación modelada de la OIT). Proporción de la } \\
\text { población masculina de un país que está empleada. }\end{array}$ & BM \\
\hline Empleadoras & $\begin{array}{l}\text { Empleadores, mujeres (\% del empleo femenino) (esti- } \\
\text { mación modelada de la OIT). Trabajadoras por cuenta pro- } \\
\text { pia o con uno o varios socios. }\end{array}$ & BM \\
\hline
\end{tabular}




\begin{tabular}{|c|c|c|}
\hline Empleadores & $\begin{array}{l}\text { Empleadores, hombres (\% del empleo masculino) (esti- } \\
\text { mación modelada de la OIT). Trabajadores varones por } \\
\text { cuenta propia o con uno o varios socios. }\end{array}$ & BM \\
\hline \multicolumn{3}{|c|}{ Variables predictoras de gobernanza y transparencia } \\
\hline Calidad regulatoria & $\begin{array}{l}\text { Incluye medidas de la incidencia de políticas hostiles al } \\
\text { mercado. Escala: -2,5 (débil) a 2,5 (fuerte). }\end{array}$ & $\begin{array}{l}\text { Indicadores } \\
\text { de Gobernan- } \\
\text { za Mundial }\end{array}$ \\
\hline Voz y responsabilidad & $\begin{array}{l}\text { Captura aspectos del proceso político, libertades civiles } \\
\text { y derechos políticos. Rango percentil: } 0 \text { (más bajo) a } 100 \\
\text { (más alto). }\end{array}$ & $\begin{array}{l}\text { Indicadores } \\
\text { de Gobernan- } \\
\text { za Mundial }\end{array}$ \\
\hline $\begin{array}{l}\text { Estabilidad política y } \\
\text { ausencia de violencia / } \\
\text { terrorismo }\end{array}$ & $\begin{array}{l}\text { Mide las percepciones de la probabilidad de que el gobierno } \\
\text { en el poder sea desestabilizado o derrocado por medios posi- } \\
\text { blemente inconstitucionales y/o violentos, incluidos la violencia } \\
\text { doméstica y el terrorismo. Escala: -2,5 (débil) a 2,5 (fuerte). }\end{array}$ & $\begin{array}{l}\text { Indicadores } \\
\text { de Gobernan- } \\
\text { za Mundial }\end{array}$ \\
\hline Estado de derecho & $\begin{array}{l}\text { Mide hasta qué punto los agentes tienen confianza en las } \\
\text { reglas de la sociedad y las acatan. Estos incluyen las per- } \\
\text { cepciones de la incidencia del delito, la eficacia y previsi- } \\
\text { bilidad del poder judicial y la exigibilidad de los contratos. } \\
\text { Escala: }-2,5 \text { (débil) a } 2,5 \text { (fuerte). }\end{array}$ & $\begin{array}{l}\text { Indicadores } \\
\text { de Gobernan- } \\
\text { za Mundial }\end{array}$ \\
\hline \multicolumn{3}{|c|}{ Variables predictoras de libertades políticas } \\
\hline Libertad de expresión & $\begin{array}{l}\text { "En la medida en que el gobierno respete la libertad de } \\
\text { prensa y los medios de comunicación, la libertad de gente } \\
\text { corriente para discutir asuntos políticos en casa y en la es- } \\
\text { fera pública, así como libertad de expresión académica y } \\
\text { cultural. Escala: } 0 \text { (más bajo) a } 1 \text { (más alto)". }\end{array}$ & VDem \\
\hline Libertades civiles & $\begin{array}{l}\text { Mide el grado en que se respetan las libertades civiles. Es- } \\
\text { cala: } 0 \text { (inferior) a } 1 \text { (superior). }\end{array}$ & VDem \\
\hline $\begin{array}{l}\text { Represión a las Orga- } \\
\text { nizaciones de la Socie- } \\
\text { dad Civil }\end{array}$ & $\begin{array}{l}\text { Captura el intento del gobierno de reprimir a las organiza- } \\
\text { ciones de la sociedad civil. Escala: desde la menos de- } \\
\text { mocrática "-3.22" hasta la más democrática "3.37". }\end{array}$ & VDem \\
\hline Democracia Electoral & $\begin{array}{l}\text { Mide hasta qué punto se alcanza el ideal de democracia } \\
\text { electoral en su sentido más amplio: liberal, participativo, } \\
\text { deliberativo, igualitario o algún otro. Escala: } 0 \text { (más bajo) } \\
\text { a } 1 \text { (más alto). }\end{array}$ & VDem \\
\hline $\begin{array}{l}\text { Libertades políticas } \\
\text { civiles }\end{array}$ & $\begin{array}{l}\text { Incluye la libertad de asociación y la libertad de expresión, } \\
\text { relevantes para la competencia política y la rendición de } \\
\text { cuentas. Escala: } 0 \text { (más bajo) a } 1 \text { (más alto). }\end{array}$ & VDem \\
\hline
\end{tabular}

Elaboración propia. 
Anexo 2

Países donantes y pesos

\begin{tabular}{|l|c|c|}
\hline \multicolumn{1}{|c|}{ Variables predictoras } & $\begin{array}{c}\text { Perú } \\
\text { unidad tratada }\end{array}$ & $\begin{array}{c}\text { Perú } \\
\text { unidad sintética }\end{array}$ \\
\hline Corrupción política 2002 & 0,522 & 0,523528 \\
Corrupción política 2003 & 0,522 & 0,523593 \\
Corrupción política 2004 & 0,522 & 0,523721 \\
Logaritmo de población & 17,10903 & 16,09963 \\
Tasa de natalidad & 22,795 & 21,38853 \\
Tasa de mortalidad & 5,581 & 8,555044 \\
Servicios básicos de agua potable & 82,58721 & 86,6805 \\
Servicios de saneamiento básico & 65,74169 & 74,50835 \\
Acceso a electricidad & 74,81867 & 80,41123 \\
Tasa de fecundidad adolescente & 60,1396 & 50,99982 \\
Esperanza de vida al nacer, mujer & 74,49467 & 72,5599 \\
Esperanza de vida al nacer, hombre & 69,16634 & 67,38094 \\
Tasa de mortalidad infantil & 23,83333 & 29,42707 \\
Participación de la fuerza laboral & 73,58766 & 61,67031 \\
Desempleo & 5,162667 & 9,342859 \\
Empleo vulnerable & 55,268 & 36,8795 \\
Logaritmo del PIB & 24,81915 & 24,12486 \\
Crecimiento del PIB & 4,858918 & 4,142026 \\
Logaritmo del PIB per cápita & 7,709396 & 8,023991 \\
Comercio* & 38,26996 & 81,93221 \\
Rentas minerales & 1,989031 & 5,265395 \\
Calidad regulatoria & 0,129756 & 0,002044 \\
Voz y responsabilidad & 50,54774 & 47,41919 \\
Estabilidad política y ausencia de violencia / terrorismo & $-1,051893$ & $-0,0689685$ \\
Estado de derecho & $-0,4929304$ & $-0,0428393$ \\
Libertad de expresión & 0,889 & 0,6781783 \\
Libertades civiles & 0,816 & 0,6969103 \\
\hline
\end{tabular}




\begin{tabular}{|l|r|r|}
\hline Represión a las organizaciones de la sociedad civil & 1,83 & 1,00891 \\
Democracia electoral & 0,791 & 0,541169 \\
Libertades políticas civiles & 0,915 & 0,691951 \\
Relación empleo / población, mujeres & 2,475667 & 1,792933 \\
Relación empleo / población, hombres & 7,242 & 4,648064 \\
Empleadoras & 60,83333 & 44,22407 \\
Empleadores & 78,93467 & 68,21512 \\
\hline
\end{tabular}

Fuente: estimación del autor con información de VDem (2019) y el Banco Mundial (2019).

\section{Anexo 3 \\ Pesos por variable predictora}

\begin{tabular}{|l|c|}
\hline \multicolumn{1}{|c|}{ País tratado } & Perú \\
\hline Algeria & Índice de corrupción política \\
\hline Angola & 0,011 \\
\hline Australia & 0,009 \\
\hline Austria & 0,008 \\
\hline Bangladesh & 0,008 \\
\hline Barbados & 0,014 \\
\hline Bielorrusia & 0,008 \\
\hline Bélgica & 0,009 \\
\hline Benín & 0,008 \\
\hline Bisáu & 0,010 \\
\hline Bolivia & 0,009 \\
\hline Bosnia y Herzegovina & 0,010 \\
\hline Botsuana & 0,009 \\
\hline Brasil & 0,008 \\
\hline Bulgaria & 0,009 \\
\hline Burundi & 0,009 \\
\hline Bután & 0,010 \\
\hline
\end{tabular}




\begin{tabular}{|l|l|}
\hline Cabo Verde & 0,008 \\
\hline Camboya & 0,013 \\
\hline Canadá & 0,008 \\
\hline Chile & 0,008 \\
\hline China & 0,009 \\
\hline Chipre & 0,008 \\
\hline Cisjordania & 0,008 \\
\hline Comoras & 0,012 \\
\hline Corea, Rep. & 0,008 \\
\hline Costa Rica & 0,008 \\
\hline Croacia & 0,017 \\
\hline Cuba & 0,009 \\
\hline Dinamarca & 0,008 \\
\hline Ecuador & 0,009 \\
\hline Egipto, Rep. Árab. & 0,014 \\
\hline El Salvador & 0,012 \\
\hline Emiratos Árabes Unidos & 0,008 \\
\hline Eritrea & 0,009 \\
\hline Eslovaquia & 0,008 \\
\hline Eslovenia & 0,009 \\
\hline España & 0,008 \\
\hline Estonia & 0,008 \\
\hline Esuatini & 0,009 \\
\hline Finlandia & 0,008 \\
\hline Fiyi & 0,008 \\
\hline Francia & 0,008 \\
\hline Gabón & 0,015 \\
\hline Gambia & 0,010 \\
\hline Georgia & 0,006 \\
\hline Grecia & 0,009 \\
\hline Haiti & 0,013 \\
\hline
\end{tabular}


Efecto de la Iniciativa de Transparencia para el sector extractivo en Perú

\begin{tabular}{|l|l|}
\hline Hungría & 0,008 \\
\hline India & 0,009 \\
\hline Irán, Rep. Islám. & 0,009 \\
\hline Irlanda & 0,008 \\
\hline Islandia & 0,008 \\
\hline Israel & 0,008 \\
\hline Jamaica & 0,008 \\
\hline Japón & 0,008 \\
\hline Jordania & 0,008 \\
\hline Kenia & 0,015 \\
\hline Kuwait & 0,009 \\
\hline Laos & 0,012 \\
\hline Letonia & 0,008 \\
\hline Líbano & 0,012 \\
\hline Lituania & 0,008 \\
\hline Luxemburgo & 0,008 \\
\hline Macedonia del Norte & 0,010 \\
\hline Malasia & 0,010 \\
\hline Malta & 0,008 \\
\hline Marruecos & 0,010 \\
\hline Mauricio & 0,009 \\
\hline Moldavia & 0,012 \\
\hline Namibia & 0,008 \\
\hline Nepal & 0,012 \\
\hline Nicaragua & 0,011 \\
\hline Nueva Zelanda & 0,008 \\
\hline Países Bajos & 0,008 \\
\hline Panamá & 0,009 \\
\hline Paquistán & 0,011 \\
\hline Paraguay & 0,022 \\
\hline Portugal & 008 \\
\hline
\end{tabular}


Carlos Olmedo Cruz e Ibeth López Cazar

\begin{tabular}{|l|l|}
\hline Qatar & 0,009 \\
\hline República Checa & 0,008 \\
\hline Ruanda & 0,009 \\
\hline Rusia & 0,012 \\
\hline Serbia & 0,011 \\
\hline Singapur & 0,008 \\
\hline Siria & 0,015 \\
\hline Sri Lanka & 0,009 \\
\hline Sudáfrica & 0,009 \\
\hline Sudán & 0,012 \\
\hline Suecia & 0,008 \\
\hline Suiza & 0,008 \\
\hline Tailandia & 0,011 \\
\hline Túnez & 0,013 \\
\hline Turquía & 0,009 \\
\hline Turkmenistán & 0,016 \\
\hline Uganda & 0,011 \\
\hline Uruguay & 0,008 \\
\hline Uzbekistán & 0,012 \\
\hline Vanuatu & 0,009 \\
\hline Venezuela, Rep. Bol. & 0,027 \\
\hline Vietnam & 0,010 \\
\hline Zimbabue & 0,011 \\
\hline
\end{tabular}

Fuente: estimación del autor con información de VDem (2019) y el Banco Mundial (2019). 